Article

\title{
Sustainable New Brick and Thermo-Acoustic Insulation Panel from Mineralization of Stranded Driftwood Residues
}

\author{
Anna Laura Pisello ${ }^{1,2, *}$, Claudia Fabiani ${ }^{2}$, Nastaran Makaremi ${ }^{2}$, Veronica Lucia Castaldo ${ }^{2}$, \\ Gianluca Cavalaglio 1,2 ${ }^{1}$ Andrea Nicolini ${ }^{1,2}$, Marco Barbanera ${ }^{1,2}$ and Franco Cotana ${ }^{1,2}$ \\ 1 Department of Engineering, University of Perugia, Via G. Duranti 93, Perugia 06125, Italy; \\ cavalaglio@crbnet.it (G.C.); andrea.nicolini@unipg.it (A.N.); barbanera@crbnet.it (M.B.); \\ cotana@crbnet.it (F.C.) \\ 2 CIRIAF-Interuniversity Research Center on Pollution and Environment "Mauro Felli", \\ University of Perugia, Via G. Duranti 67, Perugia 06125, Italy; fabiani@crbnet.it (C.F.); \\ makaremi@crbnet.it (N.M.); castaldo@crbnet.it (V.L.C.) \\ * Correspondence: anna.pisello@unipg.it; Tel.: +39-075-585-3796; Fax: +39-075-515-3321 \\ Academic Editor: Francesco Asdrubali \\ Received: 22 June 2016; Accepted: 27 July 2016; Published: 4 August 2016
}

\begin{abstract}
There is considerable interest recently in by-products for application in green buildings. These materials are widely used as building envelope insulators or blocks. In this study, an experimental study was conducted to test stranded driftwood residues as raw material for possible thermo-acoustic insulation panel and environmentally sustainable brick. The thermal and acoustic characteristics of such a natural by-product were examined. Part of samples were mineralized by means of cement-based additive to reinforce the material and enhance its durability as well as fire resistance. Several mixtures with different sizes of ground wood chips and different quantities of cement were investigated. The thermo-acoustic in-lab characterization was aimed at investigating the thermal conductivity, thermal diffusivity, volumetric specific heat, and acoustic transmission loss. All samples were tested before and after mineralization. Results from this study indicate that it is possible to use stranded driftwood residues as building materials with competitive thermo-acoustic properties. In fact, the thermal conductivity was shown to be always around $0.07 \mathrm{~W} / \mathrm{mK}$ in the unbound samples, and around double that value for the mineralized samples, which present a much higher volumetric specific heat $\left(1.6 \mathrm{MJ} / \mathrm{m}^{3} \mathrm{~K}\right)$ and transmission loss capability. The lignin powder showed a sort of intermediate behavior between the unbound and the mineralized samples.
\end{abstract}

Keywords: biomass; stranded driftwood residues; building envelope; thermal and acoustical properties; bio-based composite; energy efficiency in buildings; environmental sustainability

\section{Introduction}

\subsection{The Challenge of Biomass Resources}

Today, in both developing and developed countries, the building sector is responsible for a remarkable part of energy consumption and greenhouse gas emissions [1,2]. This fact illustrates the importance of applying energy-saving strategies in buildings' life cycle, from their construction to their disposal, in order to operate more efficiently [3-7]. Consequently, in recent years, there has been a renewed global interest in biomass energy sources as a substitute for petroleum-based resources and fossil fuels to meet the heating and cooling energy demands of buildings [8-10]. Therefore, the increasing use of biomass in the European countries can contribute towards the achievement of the Europe 2020 target of 20\% final energy consumption from renewable sources [11]. Besides, 
applications of biomass wastes, residues and by-products which can potentially be used as sustainable and environmental friendly materials are increasingly gaining attention in the building industry to mitigate the environmental impacts associated with the built environment [3-5]. Several studies in the literature have demonstrated the wide range of natural resources and biomass applications such as burning wood for heating purposes, or even growing genetically modified microbes to produce cellulosic ethanol [12-15]. Likewise, several experimental studies have been conducted to identify and analyze the potential use of biomass as building material components [16-19].

The Italian Ministry of the Environment has promoted various innovative strategies for encouraging the application of: (i) energy efficient practices and (ii) renewable energy sources. In this context, some studies have focused on recovering natural materials from wetlands or dragged on the beaches of seas, lakes and rivers in order to investigate the possibility of recycling and reusing these biomasses $[20,21]$. Italy is a long peninsula alongside surrounded by seas and therefore it has a large coastline, i.e., about $7600 \mathrm{~km}[22,23]$. Hence, the government and the related municipalities put a huge amount of economic and energy-environmental effort into collecting and disposing of driftwood residues deposited on the seashores by the tide. Just considering the shoreline management in the northern and central coastal zones, it is estimated that the management and collection of stranded driftwood residues costs annually more than 7 million Euro [23]. Consequently, exploitation of tons of biomass driftwood on the seashores not only represents a sustainable waste management solution which could even be a source of revenue for municipalities, but also it could provide clean-burning biofuels or building material resources. Additionally, such by-products could be valorized for both economic and environmental energy saving purposes in buildings, even in developing countries and emergency architectures, given the relatively simple industrialization process proposed in this work. Accordingly, the work in hand focuses on the reprocessing of driftwood found on beaches in Italy as local biomass wastes and residues for producing green building envelopes.

\subsection{Biomass Materials in Building Construction}

In the past few years, along with the growing worldwide environmental awareness for sustainable and eco-friendly development, many scholars have emphasized the need for using appropriate materials from renewable sources to optimize building energy performance. Generally speaking, in the context of energy-efficient buildings, enhancing the insulation properties of building envelopes is one of the fundamental strategies to reduce energy usage $[10,16,24,25]$. Due to both summer cooling and winter heating needs, the thermal characteristics and performance of external walls play a key role in creating a comfortable indoor climate. In addition to thermal properties, the acoustical demand of buildings, including sound absorption and sound insulation, is of great importance in order to reduce the impact of urban noise $[8,26]$. The thermal and acoustic properties of biomass materials have been widely studied recently $[27,28]$. Asdrubali et al. [16] reported on the various types of unconventional sustainable insulation materials, including natural and recycled ones, in order to emphasize the environmental advantages of using these materials. Additionally, Asdrubali et al. [29] carried out an experimental study to investigate both the thermal and acoustic performances of innovative bio-based panels made from common reed. Likewise, in a study by Schiavoni et al. a holistic comparative analysis has been done to highlight the strengths and weaknesses of the main commercialized insulation materials, including both conventional and unconventional products [24].

Recycled by-products are mostly used as a natural component of a sustainable kind of lightweight concrete (LWC) with suitable mechanical properties and higher insulation characteristics [30]. They can be used as insulation panels by adding cement as additive to bond wood chips together. Several studies have examined the effect of different bio-based materials such as hemp fibers [31], coconut shell of babaçu [32], rice straw and wood particles [33] on cement composites. Among all these biomass materials, many researchers have been focusing on the possibility of reusing wood by-products in building construction. Wood-cement board has been known for more than 100 years as one of the most popular materials in the United States and Europe for housing construction and assembly. A series 
of advantages for building applications such as dimensional stability, resistance to environmental conditions, i.e., moisture or temperature, fast, and low-cost production processes, etc. makes these wood-cement composites (WC) interesting to a large extent in the building industry [34]. In 1999, Al Rim et al. studied the effect of different wood proportions on the thermal and mechanical performance of clay-cement-wood composites [35]. Likewise, in an experimental study by Taoukil et al. the effect of moisture content on the thermal conductivity and diffusivity of wood-concrete composites was investigated [36]. Moreover, different kinds of cement bonded panels with high insulating capability made of wood particles have already been studied. Okino et al. [37] assessed the mechanical properties and natural decay of several specimens of wood cement-bonded particleboard by using six eucalypts species and two clones of rubberwood with different ratio of wood, cement and water. Similarly, Belhadj et al. (2014) in an experimental study in Algeria, demonstrated the improvement of thermal performance and physico-mechanical properties of lightweight sand concrete by the incorporation of barley straws and wood shavings as a local material in an arid zone [38]. Quiroga et al. conducted an experimental study on Populus euroamericana from subtropical forests of Argentina to investigate how wood treatment affects the mechanical properties of wood-cement composites intended for use as building materials [34]. Indeed, it has been proven by many studies that these kinds of bio-based products could be applied as sustainable and innovative alternatives to improve buildings' thermal and acoustic performance, while minimizing indoor energy requirements and the cost of materials.

According to the literature, there is still a substantial need to explore the feasibility of applying different kinds of bio-based materials, ranging from wood residues to Sansevieria fiber, as sustainable alternative building materials. Nevertheless, the use of such natural wastes could lead to a considerable minimization of the materials cost and environmental impact of the construction sector. Additionally, it could be also a much valuable income source for local governments.

In fact, the collection of such biomass and its re-use as a sustainable and high-performance building material could help governments and local municipalities reduce the current costs for collection and disposal of driftwood residues, that must be removed anyway for the maintenance of public beaches.

Moreover, the environmental impact of such innovative materials is very low, since the stranded driftwood residues are natural materials typically left on the beaches after coastal storms which currently constitute a waste to be disposed. Therefore, reusing them as brick or thermal-acoustic insulation for buildings and sustainable construction applications could lead to a significant reduction of the $\mathrm{CO}_{2}$ emissions now generated by the burning of such wastes. On the other hand, the usage of such natural material could decrease the quantity of cement typically needed in conventional building concrete-base blocks and structures.

Accordingly, the purpose of this study is to determine possible applications of stranded driftwood residues for building envelopes. Hence, this study contributes towards our understanding of the thermal and acoustic performances of the selected material in order to define the best performing mix design for large scale application purposes.

\section{Materials and Methods}

\subsection{Materials and Sample Preparation}

The stranded driftwood residues used in this study were collected in three different locations on the Italian coast, i.e., Marinella di Sarzana, Jesolo and San Benedetto del Tronto, during 2014 and 2015 (Figure 1a,b).

The material was then stored in a cool, dry place, away from sunlight to prevent mold growth and photochemical reactions, and a part of it underwent a physico-chemical characterization, which showed that about $86 \%$ of the total amount collected on the seaside had suitable characteristics to be used as building materials (Table 1). Moisture, ash, and volatile contents were determined 
according to UNI EN 15148 [39] and UNI EN 14775 [40] using a TGA-701 Thermogravimetric Analyzer (LECO Corporation, St Joseph, MI, USA). The ultimate analysis $(\mathrm{C}, \mathrm{H}, \mathrm{N})$ was performed according to UNI EN 15104 [41], using a LECO Truspec CHN analyzer, whose operation is based on a thermal conductivity method. The net calorific value analysis was carried out according to UNI EN 14918 [42] employing an isoperibolic calorimeter (mod. LECO AC350). The device gives a gross calorific value of the sample; then the net value is obtained by calculation, from moisture and hydrogen content of the sample. In order to quantify the sand content, the wood fraction was separated from the sand by wet sieving with a $2 \mathrm{~mm}$ sieve. Then, the organic fraction was completely separated from the sand by oxidation of the undersize fraction with $\mathrm{H}_{2} \mathrm{O}_{2}(30 \mathrm{~m} / \mathrm{m}$ in water) [43]. Finally, the residue was washed in running water, dried at $105^{\circ} \mathrm{C}$ and finally weighed.
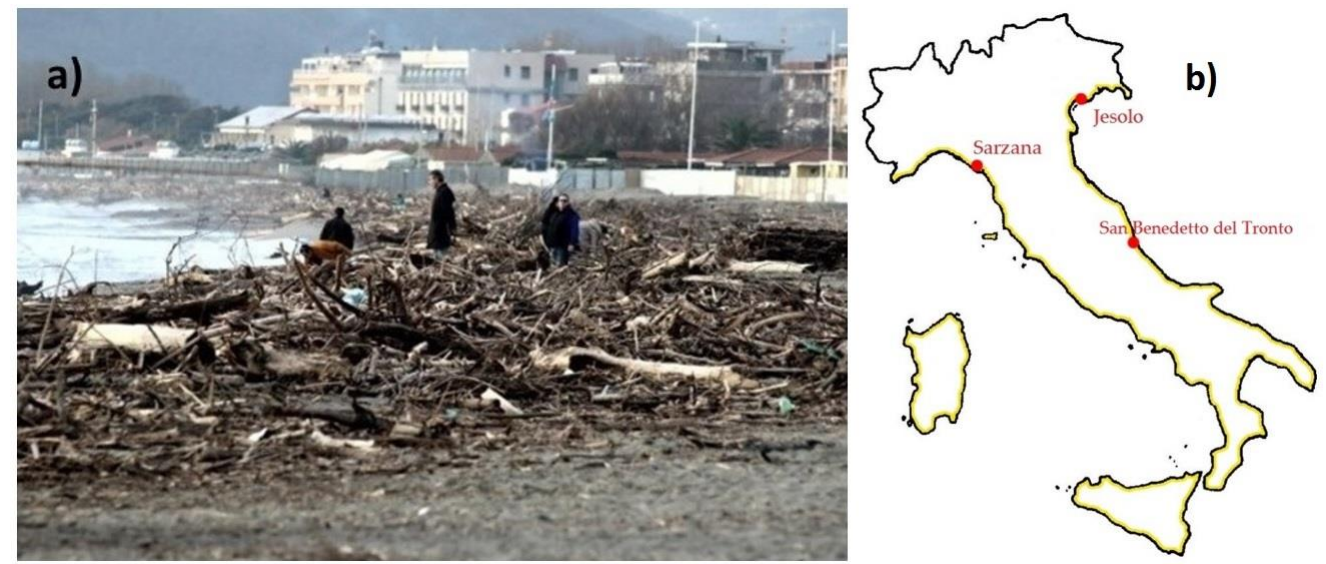

Figure 1. (a) Stranded driftwood residues; (b) The study area.

Table 1. Physico-chemical characteristics of the biomass [39-43].

\begin{tabular}{|c|c|c|c|c|}
\hline Driftwood Samples & A & B & $\mathrm{C}$ & D \\
\hline Diameter (cm) & $>4$ & $1.5<\mathrm{d}<4$ & $0.5<d<1.5$ & $\mathrm{~d}<0.5$ \\
\hline Mass fraction $(\%)$ & 46 & 40 & 8 & 6 \\
\hline Moisture content (\%) & 36.0 & 45.8 & 50.4 & 56.6 \\
\hline Salinity $(\%)$ & 0.7 & 0.6 & 3.7 & 7.4 \\
\hline Total salts content ( $\mathrm{g} / \mathrm{kg}$ ar) & 1.8 & 15.2 & 13.1 & 12.0 \\
\hline Ash content $(\%$ ar $)$ & 2.7 & 2.7 & 2.5 & 4.3 \\
\hline Ash content $(\% \mathrm{db})$ & 4.2 & 5.0 & 5.0 & 10.0 \\
\hline Volatile content ( $\%$ ar) & 57.1 & 41.7 & 42.0 & 34.7 \\
\hline Volatile content $(\% \mathrm{db})$ & 89.2 & 76.9 & 84.6 & 79.9 \\
\hline Carbon content ( $\%$ ar) & 30.1 & 25.3 & 23.3 & 19.1 \\
\hline Carbon content $(\% \mathrm{db})$ & 47.1 & 46.6 & 47.0 & 43.9 \\
\hline Hydrogen content (\% ar) & 6.8 & 7.8 & 8.1 & 8.5 \\
\hline Hydrogen content $(\% \mathrm{db})$ & 4.4 & 4.9 & 5.0 & 4.9 \\
\hline Nitrogen content ( $\%$ ar) & 0.4 & 0.7 & 0.4 & 0.4 \\
\hline Nitrogen content $(\% \mathrm{db})$ & 0.7 & 1.3 & 0.8 & 1.0 \\
\hline Higher Heating Value (MJ/kg ar) & 12.1 & 10.0 & 9.2 & 8.3 \\
\hline Higher Heating Value $(\mathrm{MJ} / \mathrm{kg} \mathrm{db})$ & 18.9 & 18.5 & 18.6 & 19.2 \\
\hline Lower Heating Value (MJ/kg ar) & 11.3 & 9.0 & 8.1 & 7.0 \\
\hline Lower Heating Value (MJ/kg db) & 18.0 & 17.5 & 17.6 & 18.2 \\
\hline
\end{tabular}

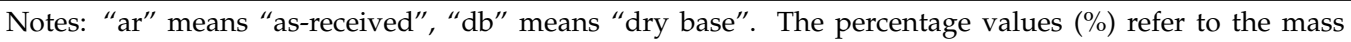
fraction $w / w$. 
Once the physico-chemical characteristics of the driftwood residues were defined, the remaining material was used to produce mineralized building blocks of a cylindrical shape, with a diameter of $100 \mathrm{~mm}$ and a total thickness of about $8 \mathrm{~mm}$. Before producing such samples, a pre-treatment process of the stranded driftwood residues had to be undertaken.

Initially, the materials underwent a hygrometric conditioning procedure in order to remove excess moisture. For this purpose, the tested material was kept in a climatic chamber for about $48 \mathrm{~h}$ at $40{ }^{\circ} \mathrm{C}$. After the drying process, the biomass was chipped to $20-30 \mathrm{~mm}$ pieces by means of a wood chip shredder (Figure 2a). The semi-finished product was then weighed and divided into four portions. One of them was set aside to be later used as a component of the different design-mixes while the others were subjected to a second chipping procedure by means of a refining mill (Figure $2 b$ ). The refining step was carried out using three grids with different hole size, i.e., 4, 2 and $1 \mathrm{~mm}$, one for each of the remaining portions of semi-finished product (Figure 2c). At the end of the stranded biomass processing, four distinct sizes of the stranded material were obtained, and three different samples of each material, i.e., 20-30, 4, 2, and $1 \mathrm{~mm}$, were analysed to define their average moisture mass per weight. The obtained results are shown in Table 2.

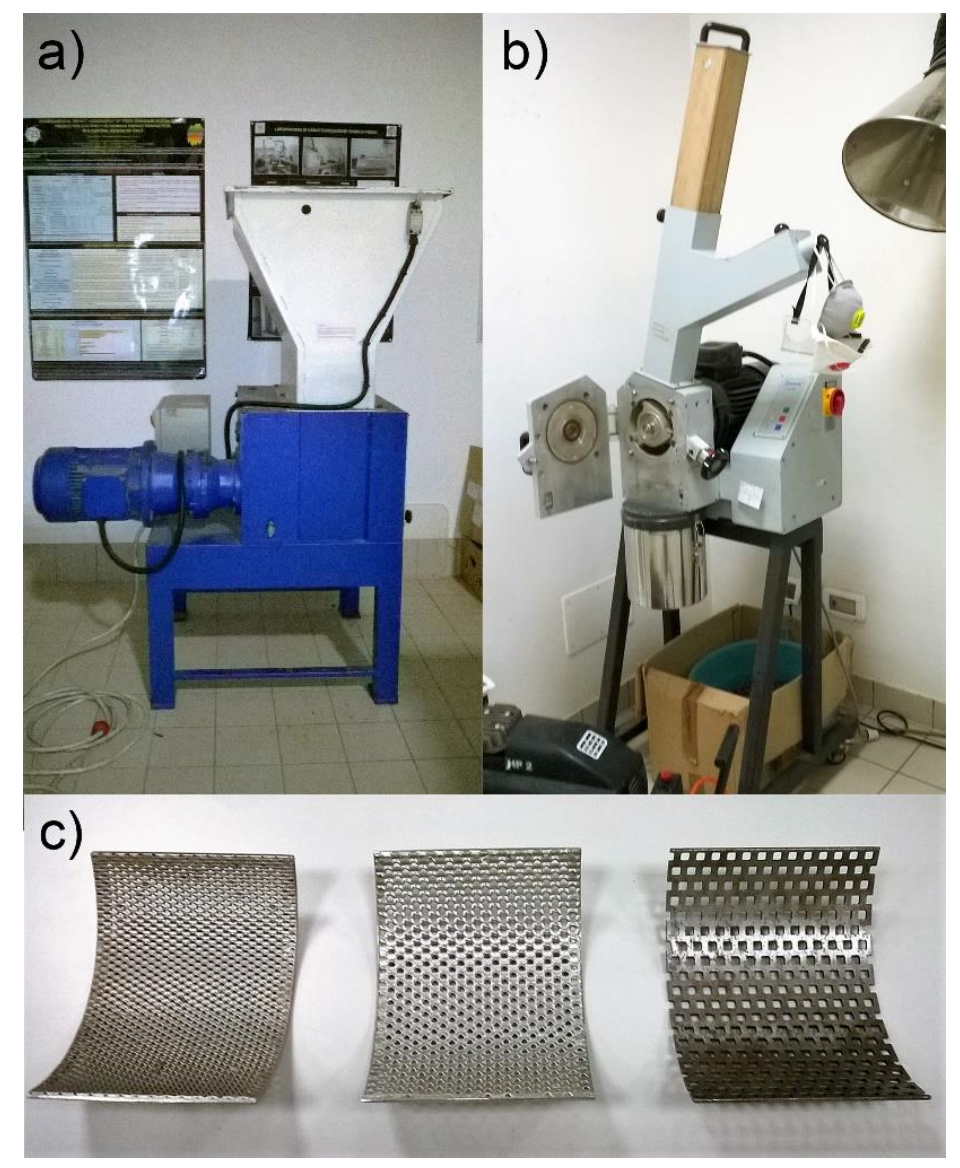

Figure 2. (a) Loose chips wood shredder; (b) Refining mill; (c) Refining mill grids.

Table 2. Biomass chips characteristics.

\begin{tabular}{ccc}
\hline Chip Size $\mathbf{( m m )}$ & Weight $\mathbf{( k g )}$ & Moisture Mass per Weight $\mathbf{( \% )}$ \\
\hline$<30$ & 1.232 & 14.26 \\
$<4$ & 1.333 & 15.68 \\
$<2$ & 1.407 & 21.21 \\
$<1$ & 1.348 & 28.06 \\
\hline
\end{tabular}


At this stage, the mineralization process was performed and the cylindrical composite prototypes were developed. In general, mineralization procedure for bio-based products is carried out by means of a preparation with a lime and/or cement-based material [44]. Accordingly, this study utilized Portland cement to ensure the cohesion of driftwood particles as a self-sustaining material for building block manufacture (Figure 3).

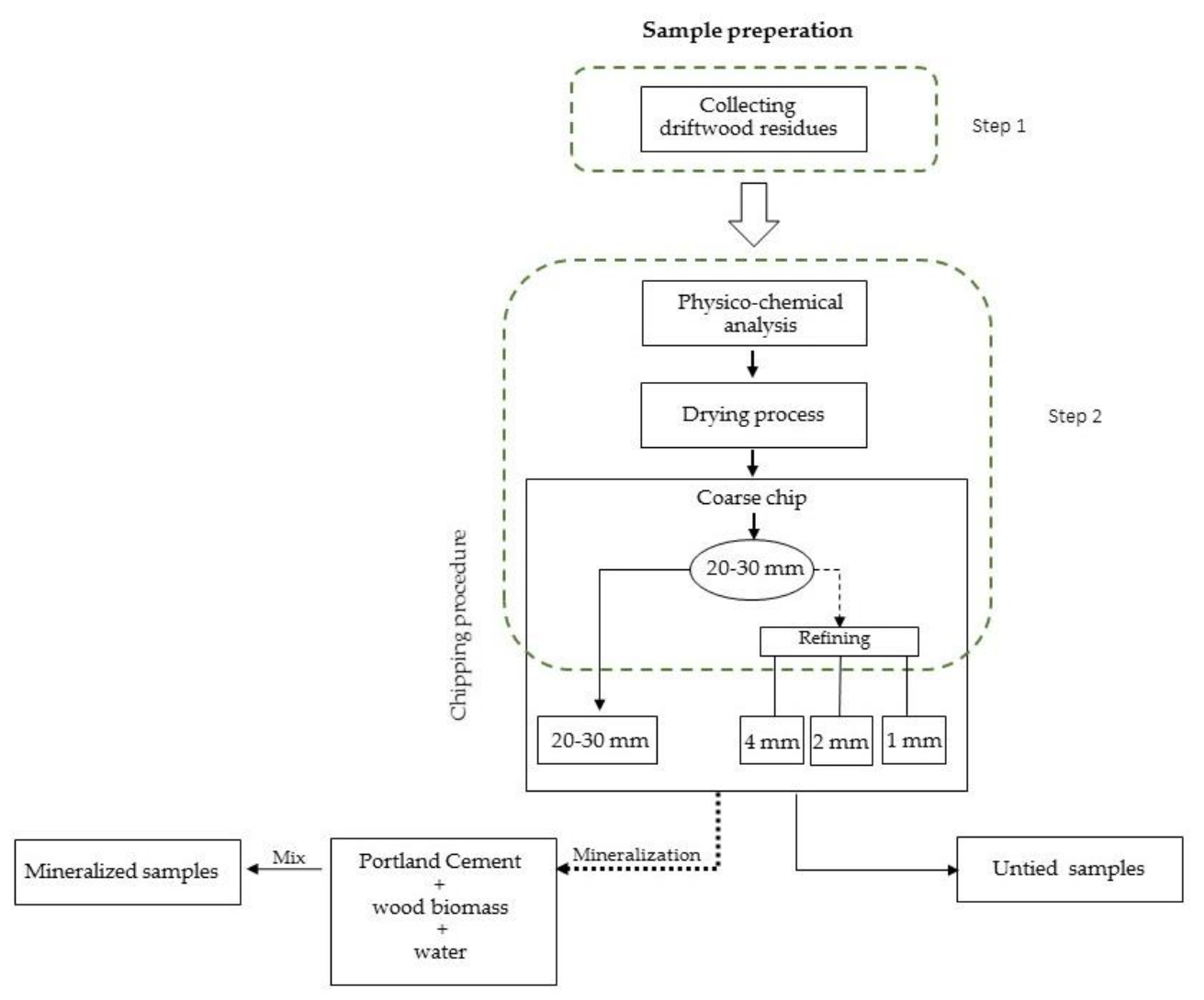

Figure 3. Schematic procedure.

In this work, both the unbound and the mineralized materials, i.e., U-samples and M-samples, respectively, were analyzed from a thermal and an acoustic point of view. In the first category, i.e., the unbound materials, the four previously produced multiple particle sizes, i.e., $<1 \mathrm{~mm}$ (sample U1), $<2 \mathrm{~mm}$ (sample U2), $<4 \mathrm{~mm}$ (sample U4), $<30 \mathrm{~mm}$ (sample U30) were investigated (Figure 4). In particular, the four tested grain sizes were selected in order to optimize the following mixture process and to characterize the biomass itself with varying simply the only cuts size. Additionally, the lignin floury size, having a cut size lower than $0.5 \mathrm{~mm}$ (sample U0), was also tested as fifth sample of the unbound category for comparison purposes.

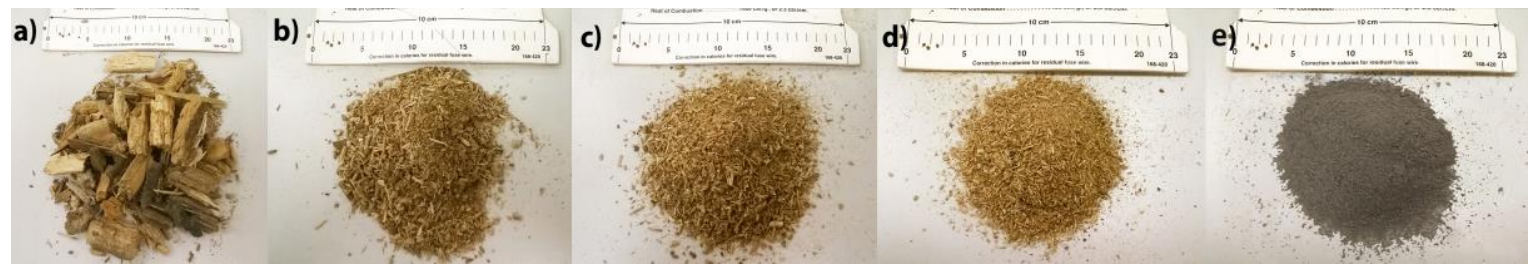

Figure 4. Pictures of the type 1 unbound material (a) 20-30 mm; (b) $4 \mathrm{~mm}$; (c) $2 \mathrm{~mm}$; (d) $1 \mathrm{~mm}$; (e) lignin flour. 
In the second category, i.e., mineralized materials, according to different recipes, the bio-based composites including driftwood residues and Portland cement were prepared (Figure 5). The four samples of this second category differ only in the percentage, weight, and size of the components, i.e., Portland cement, wood biomass, and water. The mixing ratios of the components are detailed in Table 3.
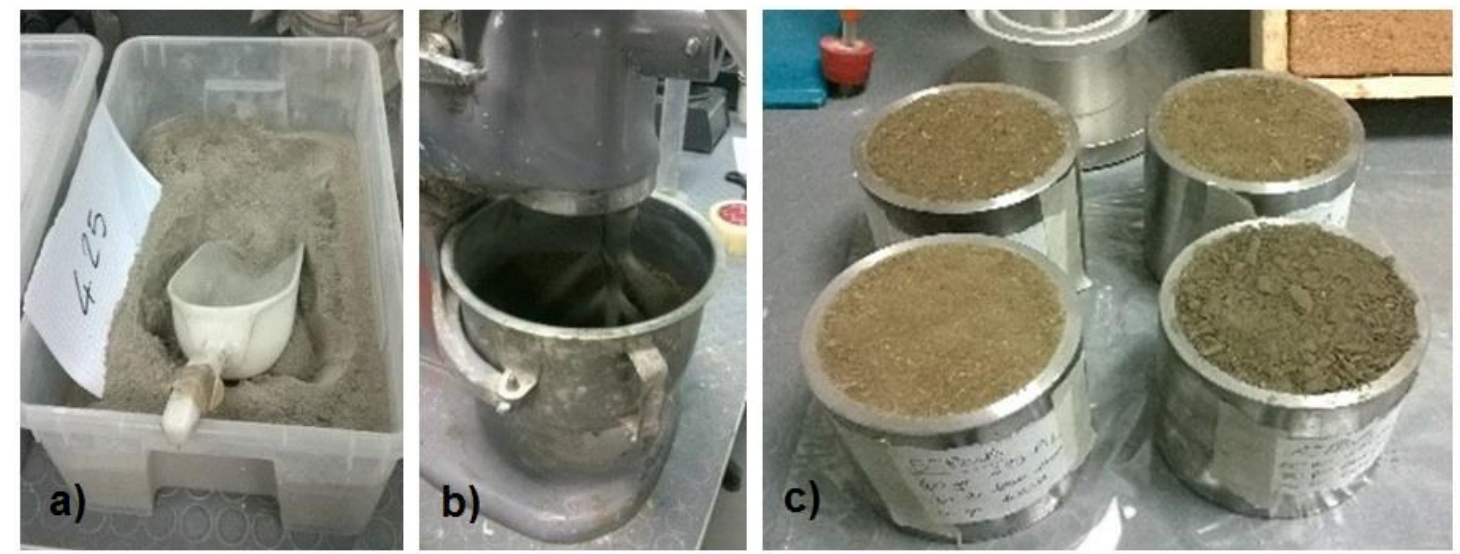

Figure 5. Mixing procedure of the mineralization process (a) Portland cement 4.25; (b) The material mixer; (c) The prepared samples and the moulds.

Table 3. Mineralized sample compositions of the M series.

\begin{tabular}{cccccccc}
\hline \multirow{2}{*}{$\begin{array}{c}\text { Sample } \\
\text { Name }\end{array}$} & \multicolumn{7}{c}{ Components } \\
\cline { 2 - 8 } & \multicolumn{2}{c}{ Portland Cement 4.25 } & \multicolumn{3}{c}{ Wood Biomass } & \multicolumn{2}{c}{ Water } \\
\cline { 2 - 8 } & $\mathbf{k g}$ & $\mathbf{\%}$ & $\mathbf{k g}$ & $\mathbf{\%}$ & \multicolumn{1}{c}{ Chip Size (mm) } & $\mathbf{~ k g}$ & $\mathbf{\%}$ \\
\hline M1 sample & 0.600 & 67 & 0.150 & 17 & $<4(\mathrm{U} 4)$ & 0.150 & 17 \\
& & & 0.075 & 8 & $<4(\mathrm{U} 4)$ & & \\
M2 sample & 0.600 & 67 & 0.0375 & 4 & $<2(\mathrm{U} 2)$ & 0.150 & 17 \\
& & & 0.0375 & 4 & $<1(\mathrm{U} 1)$ & & \\
M3 sample & 0.600 & 67 & 0.150 & 17 & $<30(\mathrm{U} 30)$ & 0.150 & 17 \\
M4 sample & 0.600 & 55 & 0.150 & 14 & $<2(\mathrm{U} 2)$ & 0.350 & 32 \\
\hline
\end{tabular}

As shown in the Table 3, the Portland cement inclusion was varied from $55 \%$ to $67 \%$ by weight concentration. After the production process and drying phases, it was observed that the M3 sample had very little damage, while the M2 and the M4 samples were partially damaged. Meanwhile, the M1 sample performed very well from a mechanical point of view.

\subsection{Thermal Characterization}

From a thermal properties point of view, a building insulation material can be defined in terms of thermal conductivity $(\lambda)$ for steady state and thermal diffusivity (D) for unsteady state conditions [26]. Hence in this study, the thermal characterization of the samples was carried out by using the Transient Plane Source (TPS) technique implemented within a Hot Disk TPS 2500 experimental facility (Hot Disk AB Company, Gothenburg, Sweden), which allows one to evaluate both these properties by means of a single measurement $[45,46]$.

The method uses a sort of metal double spiral as a thermal source (Figure 5a) and thermal probe at the same time and, from a theoretical point of view, this spiral consists of a series of concentric and equally distanced rings. From a theoretical point of view, such a transient method takes into account 
the following heat conduction equation, where the abovementioned radial symmetry of the tested sample is assumed as given in [47]:

$$
\left(\rho C_{p}\right) \frac{\partial T}{\partial t}=k_{i n} \frac{1}{r}\left(\frac{\partial}{\partial r}\left(r \frac{\partial T}{\partial r}\right)\right)+k_{t h r u} \frac{\partial^{2} T}{\partial z^{2}}+\sum_{r i n g s} Q_{r} \delta\left(r-r^{\prime}\right) \delta(z)
$$

where $\rho$ is the density of the sample $\left(\mathrm{kg} / \mathrm{m}^{3}\right), C_{p}$ is the heat capacity of the sample $(\mathrm{J} /(\mathrm{kgK})), T$ is the temperature of the sample (K), $t$ is the time of the measurement $(\mathrm{s}), k_{\text {in }}$ and $k_{\text {thru }}$ are the in-plane and through-plane thermal conductivities of the sample $(\mathrm{W} / \mathrm{mK}), \delta$ is the Dirac delta function, $r^{\prime}$ is the radius of one of the ring sources, and $Q_{r}$ is the power supplied to that ring per unit length of the ring $(\mathrm{W} / \mathrm{m})$. The total power for each ring is proportional to the circumference of the ring $2 \pi r^{\prime}$, such that the total power supplied for all of the rings is $Q(W)$. Such a parameter has to be selected according to the sample typology and its material properties.

In addition, the specific heat capacity $\left(C_{p}\right)$ of the investigated sample can also be derived by means of the following equation:

$$
\lambda=\rho C_{P} k
$$

where $\rho$ is the density, $C_{p}$ is the specific heat capacity, and $k$ is the thermal diffusivity of the sample.

The measurements were carried out according to the international ISO 22007-2 standard [48]. According to this standard, the probe, i.e., a planar $10 \mu \mathrm{m}$ thick double nickel spiral, sandwiched between two thin insulation Kapton-films of $25 \mu \mathrm{m}$, is used as both a heat source and a dynamic temperature sensor. In order to obtain representative values for the highly inhomogeneous compound materials tested by means of the Hot Disk facility, the sensor with $14.61 \mathrm{~mm}$ of radius was used to test the mineralized samples, while the one with the radius of $29.4 \mathrm{~mm}$ was used to analyze the unbound samples, i.e., the 4922 and the 5599 Kapton sensor, respectively. By using such equipment, it was possible to obtain thermal values averaged on a huge portion of the samples volume with the accuracy guaranteed by the absolute TPS measurement method that basically almost annuls the impact of thermal losses which cannot be neglected when using a more common steady-state method. During the experimental test, the probe was (i) positioned within the material properly and (ii) sandwiched between the sample and a common insulation material in order to perform two sided and single sided measurements, respectively. The measuring instrument is presented in Figure 6.
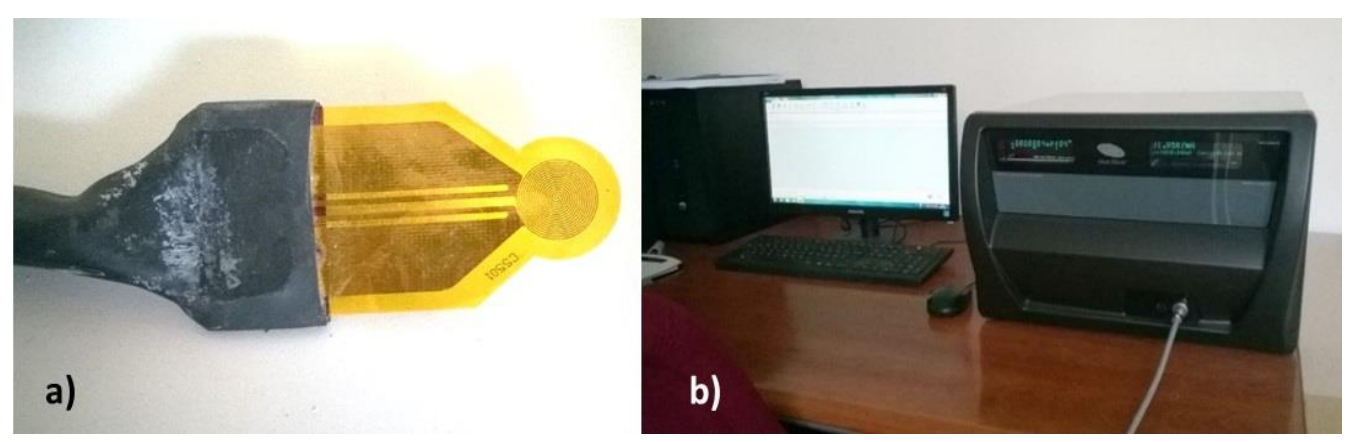

Figure 6. (a) Hot Disk sensor; and (b) Hot Disk facility.

In this regard, for testing the U-series samples, the properly sized probe was positioned within the unified particle materials, meanwhile a cement based cube was used to slightly compress the bio-based product in order to help the thermal probe adhere better to the material (see Figure 7). 

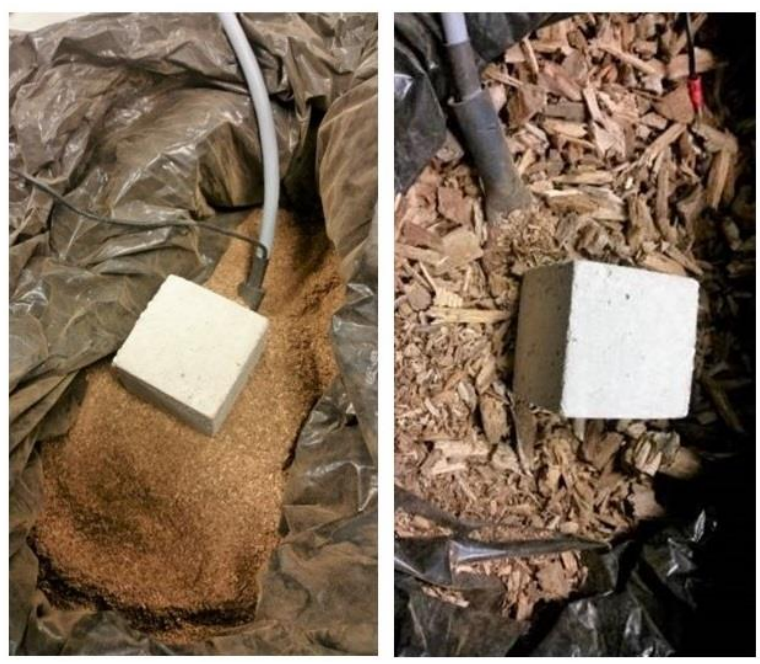

Figure 7. Probe positioning (U-series samples).

Subsequently, the M-series samples were tested while the probe was sandwiched between the biomass-based sample on one side and an insulating material on the other side as shown in Figure 8. It was assumed that the heat only transfers through the biomass-based sample. To ensure to accuracy and the reliability of the results, each measurement was repeated three times for each of the considered sample, whilst the average and standard deviation values were calculated and analyzed correspondingly.

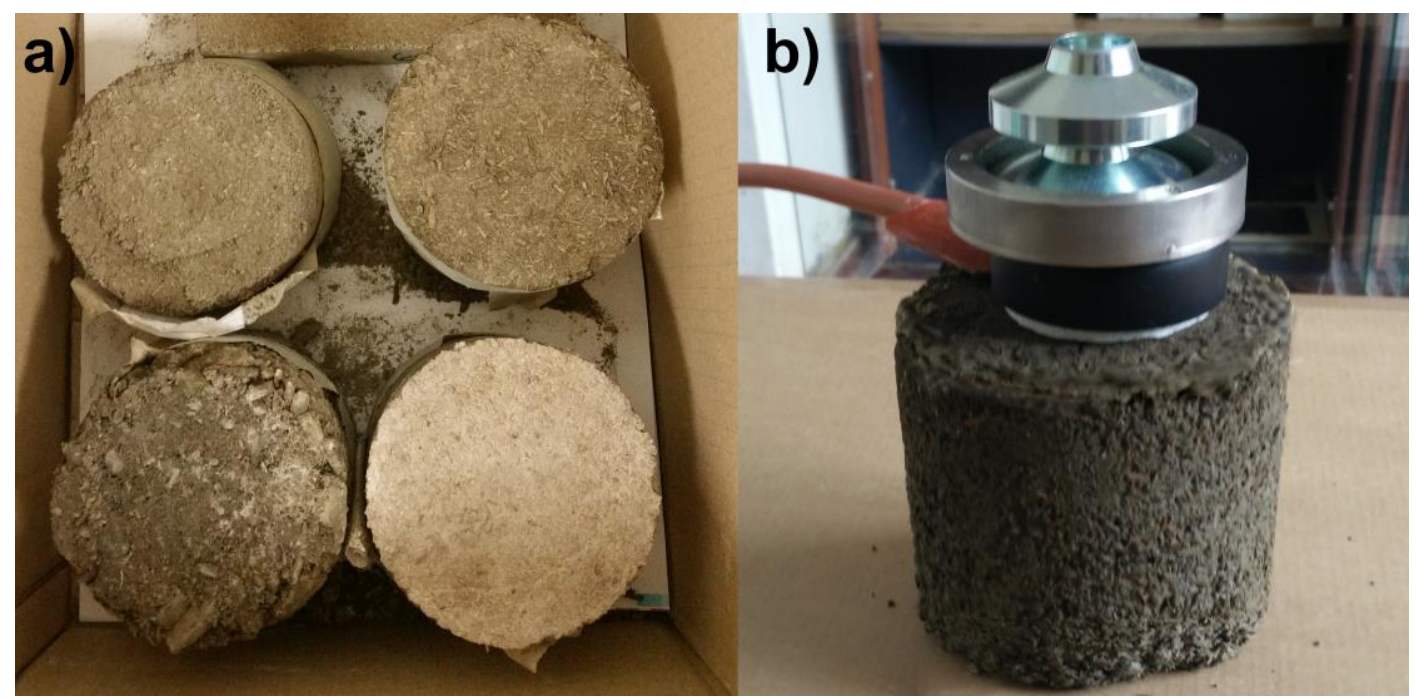

Figure 8. (a) Mineralized samples; and (b) Hot Disk sensor positioning for mineralized samples.

\subsection{Acoustic Characterization}

For the acoustic characterization of the samples, the measurements of both sound absorption and sound insulation were carried out by means of a Brüel \& Kjær model 4260 impedance tube (Brüel \& Kjær, Nærum, Denmark). The impedance tube measurements in terms of absorption coefficient and transmission loss were respectively based upon a two $(\alpha)$ and a four microphones method (TL) according to the ISO 10534-2 [49]. Both these values were evaluated for the two series of the samples, i.e., $\mathrm{U}$ and $\mathrm{M}$ samples. Furthermore, the unbound samples were investigated considering three different global thicknesses: 30, 60 and $90 \mathrm{~mm}$. Given the highly heterogeneous nature of the 
unbound materials to be tested, every measurement was taken three times, and an average absorption and insulation profile were therefore identified.

\subsubsection{Absorption Coefficient}

With the purpose of assessing the absorption coefficient, firstly the environmental parameters of the room such as atmospheric pressure, air temperature and relative humidity were measured. Afterward, the calibration procedure for the microphones was performed. Consequently, the samples were appropriately placed inside the sample holder. Eventually, the evaluation of the signal-to-noise ratio was conducted while the transfer function calibration for the channels phase displacements was evaluated. All the measurements were conducted by using the large tube configuration, i.e., with a sample diameter of $100 \mathrm{~mm}$ and covering the range of frequencies between 50 and $1600 \mathrm{~Hz}$, since for practical reasons, mineralized sample with a diameter of about $30 \mathrm{~mm}$ couldn't be produced.

Given that during acoustic measurements involving an impedance tube it is necessary to guarantee a perfect perpendicularity between the planar sound wave and the outer surface of the sample, it should be noted that, when testing $U$ samples, the tube was mounted vertically to settle the granular biomass materials (Figure 9).

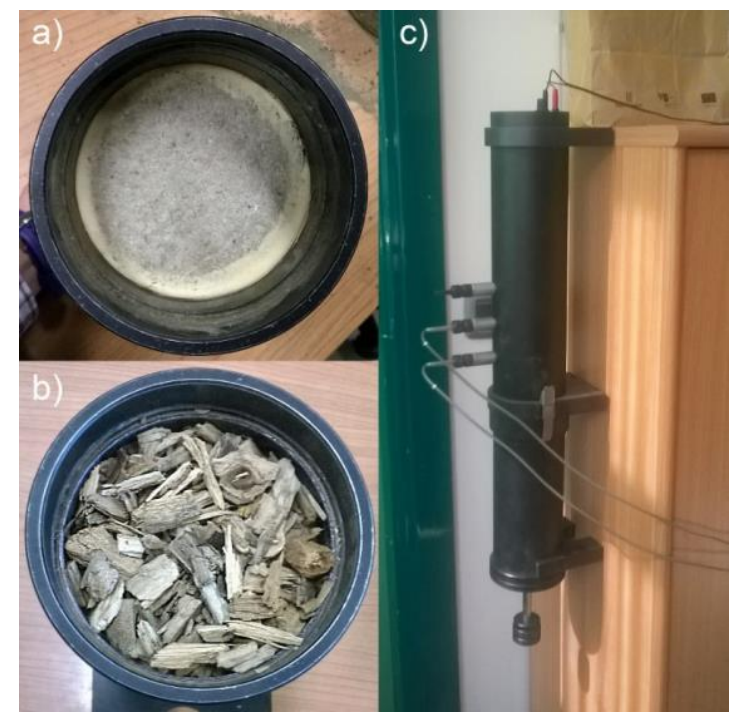

Figure 9. (a) Mineralized; (b) Unbound sample in the sample holder; and (c) Tube vertical configuration for the absorption analysis.

\subsubsection{Transmission Loss}

The acoustic insulation properties of the samples were investigated by means of the two-load method, which can be considered as an extension to four microphones of the previously presented transfer function method. In this case, the sample is placed in the middle of the tube and the acoustic field is measured both before and after the sample itself. For the evaluation of the transmission loss the environmental settings were also firstly defined and the microphones were calibrated. Secondly, two subsequent measurements were carried out, i.e., with an anechoic and a rigid termination of the tube, in order to define the background noise calibration. Finally, signal measurements were done, after the insertion of the sample, with again the anechoic and the empty end as before. All the measurements to determine the transmission loss were carried out using the large tube (sample diameter $100 \mathrm{~mm}$ ) in order to cover the range of frequencies between 50 and $1600 \mathrm{~Hz}$ for all the considered samples. Furthermore, for geometrical reasons, the unbound samples were analyzed with a vertical configuration of the tube and were held by a specifically designed sample holder, constituted by a plastic cylinder and a silicon grid (Figure 10). 


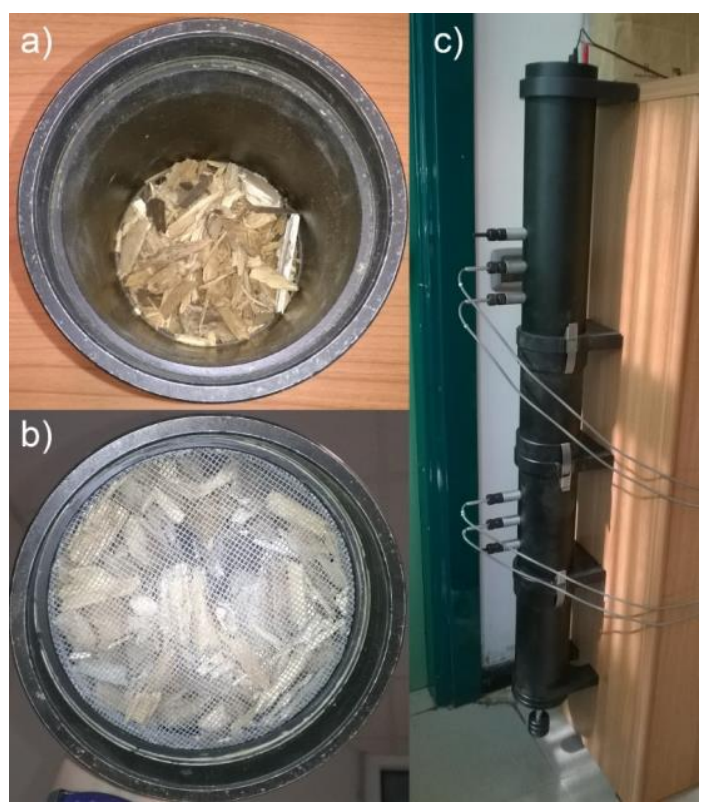

Figure 10. (a,b) Specifically designed sample holder; and (c) Tube configuration for transmission loss measurements.

\section{Results and Discussion}

\subsection{Thermal Analysis}

Results from the thermal characterization of the different samples in terms of thermal diffusivity, conductivity, and volumetric specific heat capacity are reported in Figure 11. As expected, the U- and the M-samples present completely different thermal behavior, particularly evident when both thermal conductivity and volumetric specific heat capacity are considered. The M-samples, in fact, are always associated with higher volumetric specific heat capacity values, i.e., between $0.877 \mathrm{MJ} / \mathrm{m}^{3} \mathrm{~K} \pm 0.009$ (M2 sample) and $1.653 \pm 0.008 \mathrm{MJ} / \mathrm{m}^{3} \mathrm{~K}$ (M4 sample), while the unbound samples generally are associated to $\rho C_{\mathrm{p}}$ lower than $0.314 \pm 0.007 \mathrm{MJ} / \mathrm{m}^{3} \mathrm{~K}$, with the only exception of lignin (U0 sample), which is associated with a slightly higher $\rho C_{\mathrm{p}}$ value, i.e., about $0.733 \pm 0.004 \mathrm{MJ} / \mathrm{m}^{3} \mathrm{~K}$. Looking more closely at the results, it is noteworthy that the mineralized sample with the lowest grain size and the highest water content, i.e., $\mathrm{M} 4(<2 \mathrm{~mm}$ and $0.350 \mathrm{~kg})$, is also the one with the highest thermal inertia, followed, in order, by the M3, M1 and M2 specimens, i.e., those with a fixed water content $(0.150 \mathrm{~kg})$ and decreasing chip size $(<20 \mathrm{~mm},<4 \mathrm{~mm}$ and mixed $<4$, $<2,<1 \mathrm{~mm}$ ).

The huge difference between the mineralized and the untied samples is also evident when thermal conductivity is considered. The U-samples, in fact, are always associated with $\lambda$ values lower than $0.108 \mathrm{~W} / \mathrm{mK}$, while the $\mathrm{M}$-samples $\lambda$ values are always higher than $0.239 \pm 0.005 \mathrm{~W} / \mathrm{mK}$. Focusing on the unbound materials, on the other hand, it can be observed that the lignin-based sample has the lowest thermal insulation capability, i.e., $0.108 \pm 0.005 \mathrm{~W} / \mathrm{mK}$, while there is a considerable reduction in thermal conductivity with increasing grain size distribution, i.e., from $0.077 \pm 0.002$ to $0.068 \pm 0.005 \mathrm{~W} / \mathrm{mK}$.

Lastly, when thermal diffusivity is considered, $\mathrm{M}$ - and U-samples present more similar trends, with values varying from $0.148 \pm 0.010$ to $0.397 \pm 0.008 \mathrm{~mm}^{2} / \mathrm{s}$. Samples with larger grain size, i.e., $\mathrm{U} 30$ and M2, always possess higher thermal diffusivity, i.e., $0.397 \pm 0.003$ and $0.281 \pm 0.0004 \mathrm{~mm}^{2} / \mathrm{s}$. Additionally, the $\mathrm{k}$ value associated to the lignin sample can be compared to the those of the compact mineralized samples, i.e., $0.148 \pm 0.010 \mathrm{~mm}^{2} / \mathrm{s}$ vs. $0.149 \pm 0.003,0.202 \pm 0.009$ and $0.234 \pm 0.010$ for M4, M3 and M1, respectively. 


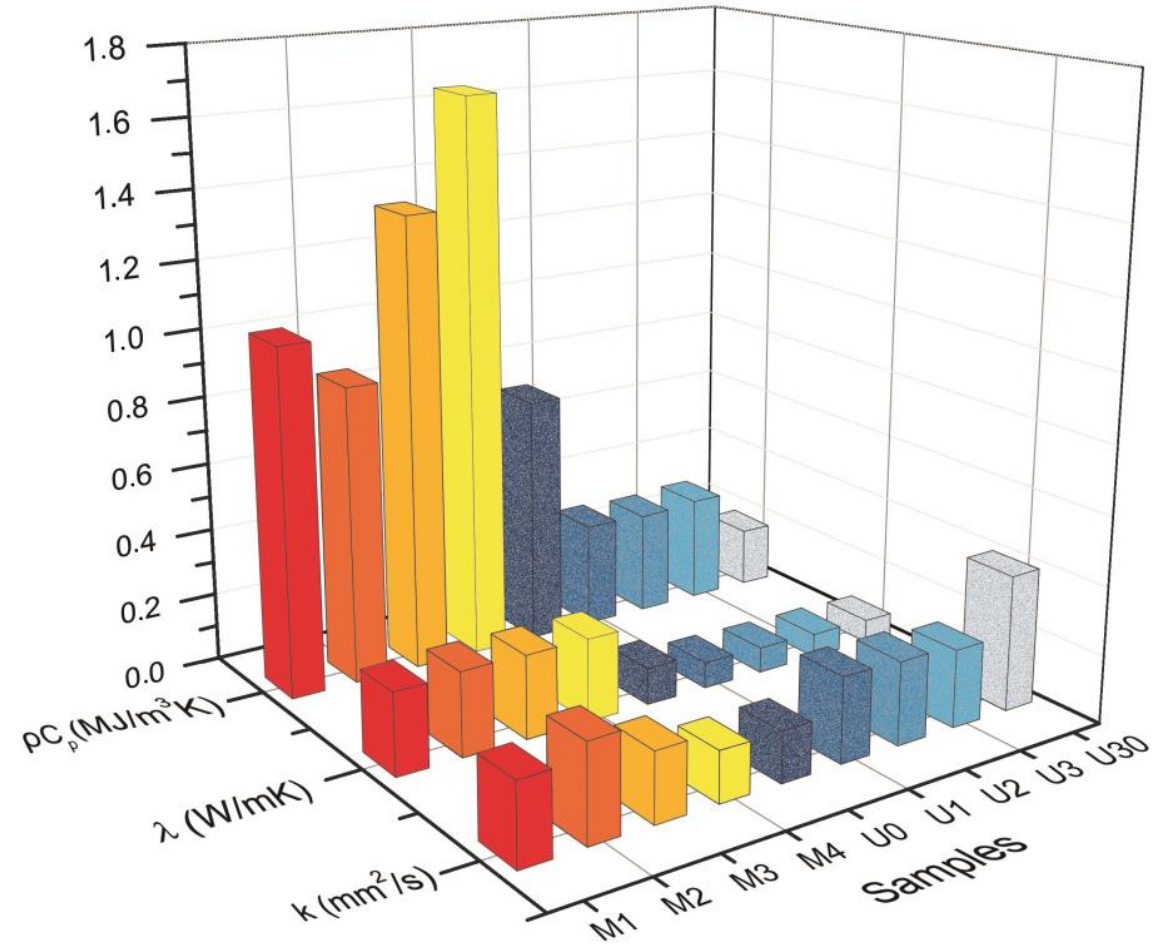

Figure 11. Thermal diffusivity $(k)$, conductivity $(\lambda)$, and volumetric specific heat capacity $\left(\rho C_{\mathrm{p}}\right)$ of the samples.

\subsection{Discussion over Thermal Results}

Results from the thermal characterization of the different samples show that the mineralized samples always present higher $\rho C_{\mathrm{p}}$ and $\lambda$ values with respect to the unbound ones, due to their more compact structure. Furthermore, significant differences can be identified between the volumetric specific heat capacity values of the different M-samples, showing that the use of lower grain sizes can produce an appreciable increase in terms of thermal inertia. The thermal conductivities of the mineralized samples, on the other hand, present a relatively low mutual difference, which suggests a lower impact of the grain size in this context.

Regarding the comparison among the $\lambda$ values of the unbound materials, it can be observed that the lignin-based sample has the lowest thermal insulation capability, while there is a considerable reduction in thermal conductivity with increasing grain size distribution. In fact, this analysis determines how the mechanical properties of the samples affect their performance and could be effective in selection/optimization procedure. The best compact samples are the ones showing a slightly higher thermal conductivity, for the lower air gap presence in the matter, also measured in sample M2, produced with a wide mix of several grain sizes. In terms of volumetric specific heat as an effective characteristic property of bio-based materials, an increase in particle size was observed to decrease volumetric specific heat value due to the existence of large air voids.

Corresponding to the thermal conductivity assessment, the samples with larger grain size such as the U30 and M2 samples characterized by large biomass grain size are considered as high thermal diffusivity materials due to their bigger air gaps. Additionally, although there was no compaction effort in the process of preparing the lignin sample, it could be compared to the compact mineralized samples because of its very fine grain size. As illustrated in the previous graph, there is no consistent trend in term of thermal diffusivity in different recipes of mineralized samples.

According to a comprehensive review of commercial and unconventional insulation materials provided by Schiavoni et al. the unbound materials, except for the lignin-based sample, could be categorized as of intermediate performance in terms of thermal conductivity [24]. The comparison of 
the achieved results with previous studies demonstrated that the range of the $\lambda$ values of the unbound materials are roughly lower compared to other products such as LECA, expanded vermiculite, cotton (stalks), and date palm [16,24]. Hence, the findings verified that there is a considerable potential in such wood residues to be used as sustainable brick or thermal insulation in sustainable construction applications as they are already waste and unusable materials.

\subsection{Acoustic Analysis}

\subsubsection{Absorption Coefficient}

Results from the acoustic absorption properties of the investigated specimens reveal a very promising behavior of the unbound samples (Figure 12) and an obviously decreased performance of the mineralized ones (Figure 13). In particular, Figure 12 clearly shows that both the chip dimensions and overall thickness of the analyzed samples affected the acoustic absorption behavior. More in details, the $\mathrm{U} 0$ sample can be associated with the worst performance in terms of acoustic absorption. The reported trend, in fact, is highly irregular and is associated to a very low average value (around 0.2) with higher but sharp peaks at lower frequencies. Sample U30 also shows a scarce absorption performance, which anyhow, increases with the thickness of the overall sample. Sample U1, on the other hand, is associated with a more stable absorption behavior, with an average value between 0.5 and 0.6 . Lastly, samples $\mathrm{U} 4$ and $\mathrm{U} 2$ are associated to an interesting absorption trend, which for higher thicknesses reaches interesting $\alpha$ values both at high and low frequencies, and an average of about 0.8 and 0.7 , respectively.

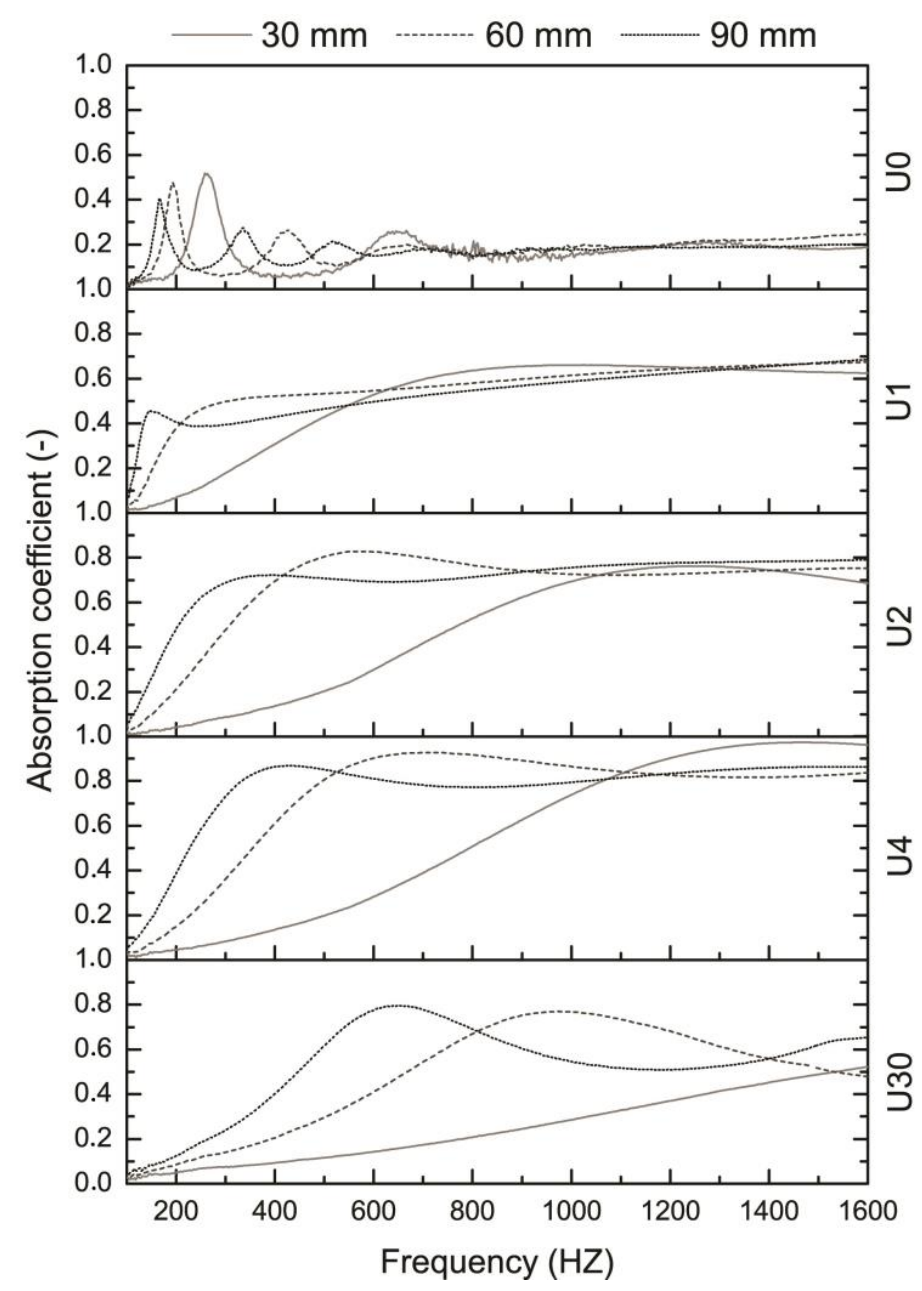

Figure 12. Absorption coefficient of the unbound samples. 


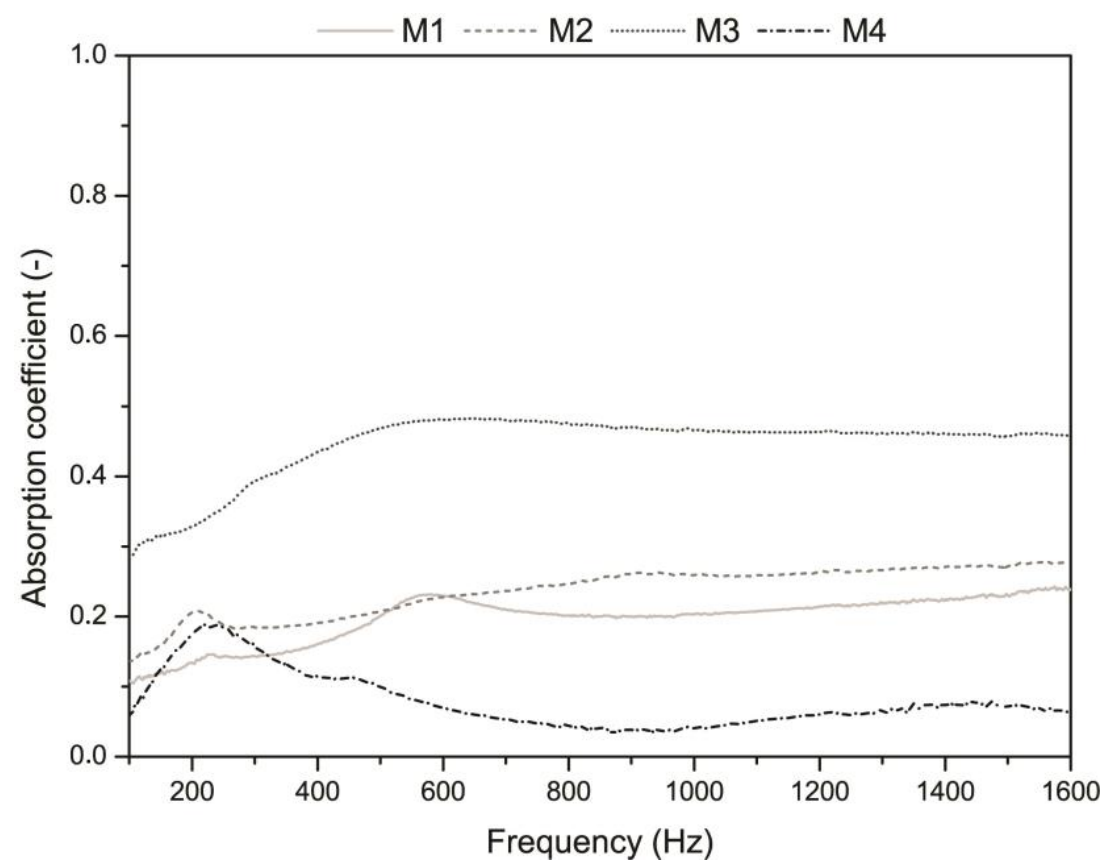

Figure 13. Absorption coefficient of the mineralized samples.

As for the mineralized samples, M1 and M2 specimens are associated to similar absorption performance, i.e., with an average $\alpha$ value of about 0.2 , while M4 seems to possess a very poor behavior, with $\alpha$ values generally lower than 0.1 . Lastly, M3 sample is the best absorbing brick, being associated to absorption coefficient values between 0.4 and 0.5 .

\subsubsection{Transmission Loss}

Considering the acoustic insulation properties of the samples, as expected, the mineralization procedure confers higher TL values to the M1-M4 samples with respect to most of the unbound specimens, with the exception of U1 sample, i.e., the one produced using chips of $1 \mathrm{~mm}$.

In general, as shown in Figure 14, the insulation trend is once again highly influenced by both the grain size and the thickness of the U-type samples. Nevertheless, when U30 and U4 specimens, which contain the coarser chips, are considered, even the highest thicknesses cannot ensure transmission loss values higher than 5 and $15 \mathrm{~dB}$, respectively. On the other hand, when the unbound samples with smaller chip dimensions are considered, i.e., U2 and U1, the TL values are highly influenced by the overall thickness of the sample. In particular, the $90 \mathrm{~mm}$ thick U1 specimen is associated to an insulation performance comparable to that of the mineralized samples (Figure 15), i.e., with an average value of about $30 \mathrm{~dB}$.

For what concerns the mineralized samples, $\mathrm{M} 2$ and $\mathrm{M} 3$ bricks possess a very similar growing insulation trend with an average value around $30 \mathrm{~dB}$, while M4 is associated to the lower TL values. Lastly, M1 sample shows an interesting TL trend, growing with frequency, and reaches the highest transmission loss value at $1600 \mathrm{~Hz}$, i.e., about $55 \mathrm{~dB}$. 


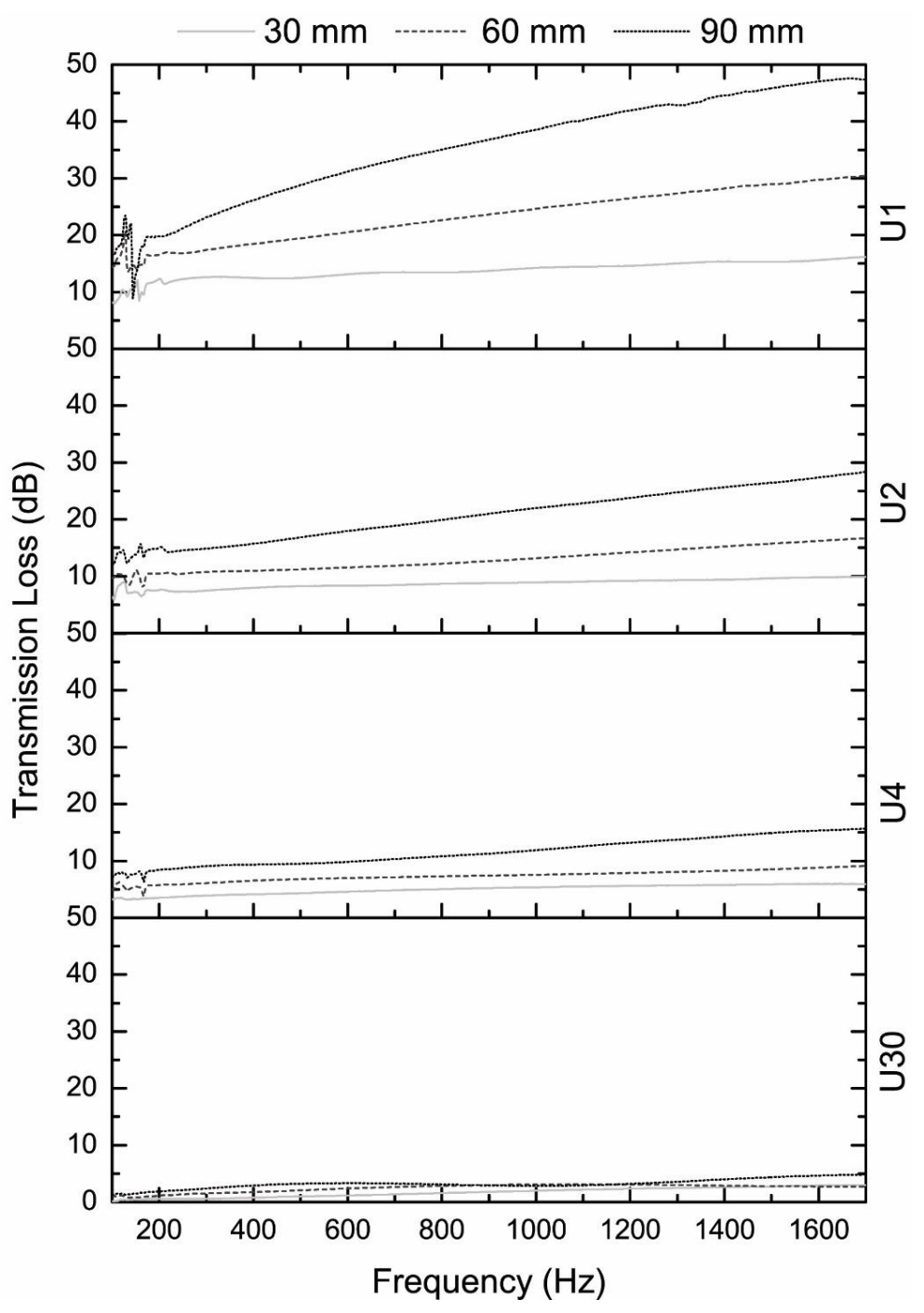

Figure 14. Transmission loss of the unbound samples.

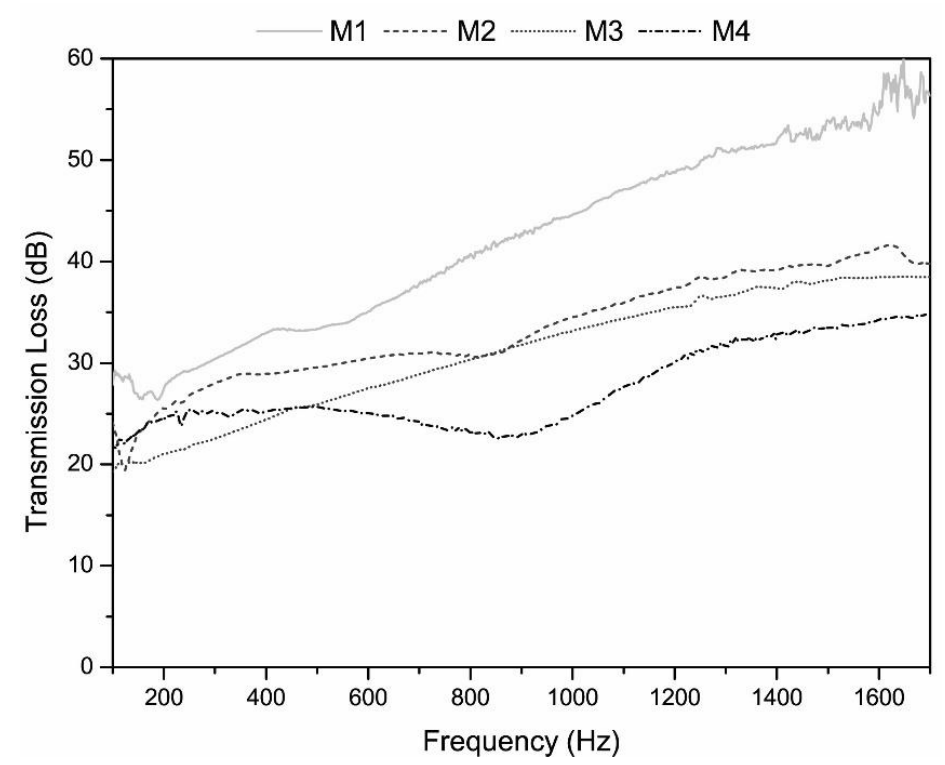

Figure 15. Transmission loss of the mineralized samples. 


\subsection{Discussion of the Acoustic Performance}

Generally speaking, the investigated samples show an interesting behavior both in terms of absorption and insulation properties. In particular, the obtained results show that the unbound materials, given their high porosity, can be considered as suitable candidates to produce acoustic absorbing panels. As expected, increasing the thickness of the unbound substrates always produces higher absorption values, especially at lower frequencies, except for the lignin sample U0, which on the contrary doesn't seem to be highly affected by such parameter. Furthermore, concerning the grain size, the most promising dimensions to be used are those of the U4 and U2 samples, characterized by 4 and $2 \mathrm{~mm}$ wood chips, respectively. These kind of chips, in fact, combine the huge quantity of interconnected pores ensured by the use of small grains, with the high air percentage in the medium, which on the other hand, is maximized when bigger chips are considered. Hence, according to the overall evaluation of the acoustic properties, it is revealed that the unbound samples with medium chip sizes have good sound absorption performance in the frequency range of 50 to $1600 \mathrm{~Hz}$ and the absorption coefficient values are approximately comparable to other common sound absorption materials such as waste wool fibers [50]. As for the mineralized samples, because of their manufacturing process such materials do not present a huge number of interconnected voids. For this reason, even though a high percentage of driftwood residues is included inside these bricks, their absorption properties cannot be considered as acceptable for an absorbing material. Nevertheless, their use can be considered as a promising way to produce lightweight concretes from residues that would otherwise be discarded in a landfill or burnt. Furthermore, some considerations can also be made about the impact of the chip dimensions on the absorption properties of the mineralized samples. The best performing M-type specimen, in fact is the one using the U30 unbound material, which clearly is more suitable to be used as high-insulation aggregate for lightweight concretes. If the mineralization process can be considered as a damaging factor for the absorption properties of the materials, when it comes to acoustic insulation, it clearly is an advantage. The mineralized samples, in fact, are denser than the unbound ones and are associated with interesting transmission loss values. It is anyhow very interesting to point out that $90 \mathrm{~mm}$ thick samples with smaller chip dimensions show highly increased insulation behaviors and reduced absorption ones. This is probably due to the higher compaction grade produced by the combination of geometry and physical, i.e., weight, reasons. The findings are in accordance with previous research demonstrating the effect of particle size distribution and degree of compaction on the acoustic properties of the material [26].

Hence, from an acoustic point of view, it could be concluded that driftwood residues show considerable potential in terms of sound insulation and absorption as an innovative and sustainable material for more environmentally friendly building material development. However, still there is a need to optimize and define the best performing mix design through using accurate grain sizes and thicknesses for real scale application targets.

\section{Conclusions}

This research focused on the evaluation of the thermal and acoustic performance of stranded driftwood residues to investigate the possibility of applying such biomass in the production of building envelope materials with improved thermal and acoustic properties. In order to achieve this objective, a broad experimental analysis involving thermal conductivity, thermal diffusivity, volumetric specific heat capacity as well as absorption coefficient and transmission loss was conducted for both unbound and mineralized samples.

Firstly, the unbound materials with different biomass chip sizes were analyzed to evaluate their thermal behavior since they are considered for use as fillers for envelope gaps or internal gypsumbased partition cavities, then the mineralized samples were also tested. From a thermal point of view, the results demonstrated that the mineralization procedure causes a general decrease of thermal conductivity and an increase of volumetric specific heat capacity with respect to the unbound materials. Furthermore, the increase in the thermal inertia of the materials can be considered as a function of 
the grain size distribution, while the increase of thermal conductivity does not seem to be highly related to such parameter. In general, however, the inner capability of the U-samples to act as proper thermal insulators, i.e., $\lambda$ values in the range $0.068-0.077 \mathrm{~W} / \mathrm{mK}$, also produced interesting thermal insulation properties in the mineralized samples. As expected, the mineralized samples also present a very promising volumetric specific heat capacity, i.e., from 0.9 to $1.7 \mathrm{MJ} / \mathrm{m}^{3} \mathrm{~K}$, together with interesting thermal conductivity values, i.e., of the same order of magnitude as porous bricks. Additionally, the mutual difference in terms of thermal conductivity observed in the mineralized samples showed that, for thermal purposes, they could be indiscriminately chosen.

From an acoustical point of view, the unbound materials showed significant absorption properties and can thus be considered suitable candidates to produce acoustic absorbing panels. The mineralization procedure highly reduces the absorption coefficient value, since the manufacturing process causes a general densification of the material and a consequent huge reduction of the number of interconnected voids which can dissipate the acoustic waves inside the specimen. Mineralized samples, on the other hand, can be considered as interesting sound insulation materials, given their higher density and capability to reduce sound transmission through the building wall.

In conclusion, this work demonstrated the feasibility of using stranded driftwood residues as components for the production of high thermal and acoustic performance building elements. Furthermore, the investigation of the prepared mix designs identified the main characteristics that should be associated to the biomass grain size and mineralization procedure in order to obtain suitable thermal and acoustic properties.

As a future development of this work, a specifically designed optimization procedure could be developed in order to produce building components characterized by: (i) high insulation properties; or (ii) high acoustic absorbing performance starting from waste. In fact, such a widely available natural material currently represents just a kind of waste to be removed from beaches, while it could represent a sustainable and low-impact construction material given its good thermal-acoustic properties. Therefore, it could be used as brick or thermal-acoustic insulation panel in low-carbon construction projects, especially in new developing countries. Therefore, the further developments of this study will be focused on the structural, life cycle and durability assessment of the new composite bio-based material, which will be ready for the potential market, since it was shown to represent a possible competitor of classic thermal and acoustic insulation materials for building envelope.

Moreover, future research could investigate additional properties of the proposed bio-based product, i.e., structural and durability properties, by performing specific tests and measurement campaigns on bigger samples.

Acknowledgments: The authors would like to thank Gabriele Franceschetti and CVR s.r.l. for assisting the mineralization procedure of the samples. Anna Laura Pisello's acknowledgments are due to the "CIRIAF program for UNESCO" in the framework of the UNESCO Chair "Water Resources Management and Culture", for supporting her research. The research was founded by the Italian Environmental Ministry with an agreement entitled "Recovery and energy valorization of stranded driftwood residues" in 2014-2016. The research team leading to these results has received funding from the European Union's Horizon 2020 research and innovation programme under grant agreement No. 657466 (INPATH-TES) and No. 678407 (ZERO-PLUS).

Author Contributions: The authors equally contributed to the development of the work, from the experimental analysis of the biomasses to the new characterization and optimization, up to the paper writing.

Conflicts of Interest: The authors declare no conflict of interest.

\section{References}

1. Hendricks, A.M.; Wagner, J.E.; Volk, T.A.; Newman, D.H.; Brown, T.R. A cost-effective evaluation of biomass district heating in rural communities. Appl. Energy 2016, 162, 561-569. [CrossRef]

2. Vilčeková, S.; Čuláková, M.; Burdová, E.K.; Katunská, J. Energy and environmental evaluation of non-transparent constructions of building envelope for wooden houses. Energies 2015, 8, 11047-11075. [CrossRef] 
3. Serrano, S.; de Gracia, A.; Cabeza, L.F. Adaptation of rammed earth to modern construction systems: Comparative study of thermal behavior under summer conditions. Appl. Energy 2016, 175, 180-188. [CrossRef]

4. Serrano, S.; Barreneche, C.; Cabeza, L.F. Use of by-products as additives in adobe bricks: Mechanical properties characterisation. Construct. Build. Mater. 2016, 108, 105-111. [CrossRef]

5. Rincón, L.; Serrano, S.; Cabeza, L.F.; González, B.; Navarro, A.; Bosch, M. Experimental rammed earth prototypes in Mediterranean climate. In Earthen Architecture: Past, Present and Future; CRC Press/Balkema: Leiden, The Netherlands, 2014; pp. 311-316.

6. Huang, H.S.; Su, C.H.; Li, C.B.; Lin, C.Y.; Lin, C.C. Enhancement of fire safety of an existing green building due to natural ventilation. Energies 2016, 9, 192. [CrossRef]

7. Pisello, A.L. Experimental analysis of cool traditional solar shading systems for residential buildings. Energies 2015, 8, 2197-2210. [CrossRef]

8. Oldham, D.J.; Egan, C.A.; Cookson, R.D. Sustainable acoustic absorbers from the biomass. Appl. Acoust. 2011, 72, 350-363. [CrossRef]

9. Maderuelo-Sanz, R.; Nadal-Gisbert, A.V.; Crespo-Amorós, J.E.; Parres-García, F. A novel sound absorber with recycled fibers coming from end of life tires (ELTs). Appl. Acoust. 2012, 73, 402-408. [CrossRef]

10. Binici, H.; Aksogan, O.; Demirhan, C. Mechanical, thermal and acoustical characterizations of an insulation composite made of bio-based materials. Sustain. Cities Soc. 2016, 20, 17-26. [CrossRef]

11. European Parliament. Directive 2009/28/EC of the European Parliament and of the Council of the 23 April 2009 on the promotion of the Use of Energy from Renewable Sources and Amending and Subsequently Repealing Directives 2001/77/EC and 2003/30/EC; Official Journal of the European Union: Bruxelles, Belgium, 2009.

12. Salata, F.; Coppi, M. A first approach study on the desalination of sea water using heat transformers powered by solar ponds. Appl. Energy 2014, 136, 611-618. [CrossRef]

13. Cotana, F.; Cavalaglio, G.; Pisello, A.L.; Gelosia, M.; Ingles, D.; Pompili, E. Sustainable ethanol production from common reed (Phragmites australis) through simultaneuos saccharification and fermentation. Sustainability 2015, 7, 12149-12163. [CrossRef]

14. Verma, V.K.; Bram, S.; Delattin, F.; Laha, P.; Vandendael, O.; Hubin, A. Agropellets for domestic heating boilers: Standard laboratory and real life performance. Appl. Energy 2012, 90, 17-23. [CrossRef]

15. Maekala, N.K.; Potumarthi, R.; Baadhe, R.R.; Gupta, V.K. Current bioenergy researches: Strengths and future challenges. In Bioenergy Research: Advances and Applications, 1st ed.; Gupta, V.J., Tuohy, M., Kubicek, C.P., Saddler, J., Xu, F., Eds.; Elsevier: Amsterdam, The Netherlands, 2014; pp. 1-495.

16. Asdrubali, F.; D'Alessandro, F.; Schiavoni, S. A review of unconventional sustainable building insulation materials. Sustain. Mater. Technol. 2015, 4, 1-17. [CrossRef]

17. Barbieri, L.; Andreola, F.; Lancellotti, I.; Taurino, R. Management of agricultural biomass wastes: Preliminary study on characterization and valorisation in clay matrix bricks. Waste Manag. 2013, 33, 2307-2315. [CrossRef] [PubMed]

18. Zhang, J.; Rajkhowa, R.; Li, J.L.; Liu, X.Y.; Wang, X.G. Silkworm cocoon as natural material and structure for thermal insulation. Mater. Des. 2013, 49, 842-849. [CrossRef]

19. Corscadden, K.W.; Biggs, J.N.; Stiles, D.K. Sheep's wool insulation: A sustainable alternative use for a renewable resource? Resour. Conserv. Recycl. 2014, 86, 9-15. [CrossRef]

20. Sgroi, F.; Di Trapani, A.M.; Foderà, M.; Testa, R.; Tudisca, S. Economic assessment of Eucalyptus (spp.) for biomass production as alternative crop in Southern Italy. Renew. Sustain. Energy Rev. 2015, 44, 614-619. [CrossRef]

21. Colantoni, A.; Delfanti, L.; Recanatesi, F.; Tolli, M.; Lord, R. Land use planning for utilizing biomass residues in Tuscia Romana (central Italy): Preliminary results of a multi criteria analysis to create an agro-energy district. Land Use Policy 2016, 50, 125-133. [CrossRef]

22. Central Intelligence Agency (CIA). Available online: https://www.cia.gov/library/publications/the-worldfactbook/fields/2060.html (accessed on 20 July 2016).

23. Cavalaglio, G.; Gelosia, M.; D’Antonio, S.; Nicolini, A.; Pisello, A.L.; Barbanera, M.; Cotana, M. Lignocellulosic ethanol production from the recovery of stranded driftwood residues. Energies 2016, 9. in press.

24. Schiavoni, S.; Bianchi, F.; Asdrubali, F. Insulation materials for the building sector: A review and comparative analysis. Renew. Sustain. Energy Rev. 2016, 62, 988-1011. [CrossRef] 
25. Iodice, P.; Massarotti, N.; Mauro, A. Effects of inhomogeneities on heat and mass transport phenomena in thermal bridges. Energies 2016, 9, 126. [CrossRef]

26. Glé, P.; Gourdon, E.; Arnaud, L. Acoustical properties of materials made of vegetable particles with several scales of porosity. Appl. Acoust. 2011, 72, 249-259. [CrossRef]

27. Gutierrez, A.; Miró, L.; Gil, A.; Rodríguez-Aseguinolaza, J.; Barreneche, C.; Calvet, N.; Py, X.; Fernández, A.I.; Grágeda, M.; Ushak, S.; et al. Advances in the valorization of waste and by-product materials as thermal energy storage (TES) materials. Renew. Sustainable Energy Rev. 2016, 59, 763-783. [CrossRef]

28. Pérez, G.; Coma, J.; Barreneche, C.; de Gracia, A.; Urrestarazu, M.; Burés, S.; Cabeza, L.F. Acoustic insulation capacity of Vertical Greenery Systems for buildings. Appl. Acoust. 2016, 110, 218-226. [CrossRef]

29. Asdrubali, F.; Bianchi, F.; Cotana, F.; D’Alessandro, F.; Pertosa, M.; Pisello, A.L.; Schiavoni, S. Experimental thermo-acoustic characterization of innovative common reed bio-based panels for building envelope. Build. Environ. 2016, 102, 217-229. [CrossRef]

30. Coatanlem, P.; Jauberthie, R.; Rendell, F. Lightweight wood chipping concrete durability. Constr. Build. Mater. 2006, 20, 776-781. [CrossRef]

31. Li, Z.; Wang, X.; Wang, L. Properties of hemp fibre reinforced concrete composites. Compos. Part A 2006, 37, 497-505. [CrossRef]

32. Almeida, R.R.; Del Menezzi, C.H.S.; Teixeira, E.D. Utilization of the coconut shell of babaçu (Orbignya sp.) to produce cement-bonded particleboard. Bioresour. Technol. 2002, 85, 159-163. [CrossRef]

33. Yang, H.S.; Kim, D.J.; Kim, H.J. Rice straw-wood particle composite for soundabsorbing wooden construction materials. Bioresour. Technol. 2003, 86, 117-121. [CrossRef]

34. Quiroga, A.; Marzocchi, V.; Rintoul, I. Influence of wood treatments on mechanical properties of wood-cement composites and of Populus Euroamericana wood fibers. Compos. Part B Eng. 2016, 84, 25-32. [CrossRef]

35. Al Rim, K.; Ledhem, A.; Douzane, O.; Dheilly, R.M.; Queneudec, M. Influence of the proportion of wood on the thermal and mechanical performances of clay-cement-wood composites. Cem. Concr. Compos. 1999, 21, 269-276. [CrossRef]

36. Taoukil, D.; el Bouardi, A.; Sick, F.; Mimet, A.; Ezbakhe, H.; Ajzoul, T. Moisture content influence on the thermal conductivity and diffusivity of wood-concrete composite. Constr. Build. Mater. 2013, 48, 104-115. [CrossRef]

37. Okino, E.Y.A.; de Souza, M.R.; Santana, M.A.E.; Alves, M.V.D.S.; de Sousa, M.E.; Teixeira, D.E. Cement-bonded wood particleboard with a mixture of eucalypt and rubberwood. Cem. Concr. Compos. 2004, 26, 729-734. [CrossRef]

38. Belhadj, B.; Bederina, M.; Montrelay, N.; Houessou, J.; Quéneudec, M. Effect of substitution of wood shavings by barley strawson the physico-mechanical properties of lightweight sand concrete. Constr. Build. Mater. 2014, 66, 247-258. [CrossRef]

39. UNI EN 15148. Solid biofuels. In Determination of the Content of Volatile Matter; Italian Standards: Rome, Italy, 2010.

40. UNI EN 14775. Solid biofuels. In Determination of Ash Content; Italian Standards: Rome, Italy, 2010.

41. UNI EN 15104. Solid biofuels. In Determination of Total Content of Carbon, Hydrogen and Nitrogen-Instrumental Methods; Italian Standards: Rome, Italy, 2011.

42. UNI EN 14918. Solid biofuels. In Method for the Determination of Calorific Value; Italian Standards: Rome, Italy, 2010.

43. ANPA. Metodi di Analisi del Compost. Manuali e Linee Guida 3/2001. ANPA-Unità Normativa Tecnica, ISDN 88-448-0258-9. Available online: http://www.isprambiente.gov.it/it/pubblicazioni/manuali-e-lineeguida/metodi-di-analisi-del-compost (accessed on 20 July 2016).

44. Vo, L.T.; Navard, P. Treatments of plant biomass for cementitious building materials-A review. Construct. Build. Mater. 2016, 121, 161-176. [CrossRef]

45. Zhang, H.; Li, M.J.; Fang, W.Z.; Dan, D.; Li, Z.Y.; Tao, W.Q. A numerical study on the theoretical accuracy of film thermal conductivity using transient plane source method. Appl. Therm. Eng. 2014, 72, 62-69. [CrossRef]

46. Berge, A.; Adl-Zarrabi, B.; Hagentoft, C.E. Determination of specific heat capacity by transient plane source. Front. Archit. Res. 2013, 2, 476-482. [CrossRef] 
47. Gustavsson, M.; Karawacki, E.; Gustafsson, S.E. Thermal conductivity, thermal diffusivity and specific heat of thin samples from transient measurements with hot disk sensors. Rev. Sci. Instruct. 1994, 65, 3856. [CrossRef]

48. International Organization for Standardization. Plastics-Determination of Thermal Conductivity and Diffusivity_Part 2: Transient Plane Source (Hot Disk) Method (SS-EN ISO 22007-2:2015); International Organization for Standardization (ISO): Geneva, Switzerland, 2015.

49. International Organization for Standardization. Acoustics-Determination of Sound Absorption Coefficient and Impedance in Impedance Tubes-Part 2: Transfer-Function Method (ISO 10534-2); International Organization for Standardization (ISO): Geneva, Switzerland, 1998.

50. Patnaik, A.; Mvubu, M.; Muniyasamy, S.; Botha, A.; Anandjiwala, R.D. Thermal and sound insulation materials from waste wool and recycled polyester fibers and their biodegradation studies. Energy Build. 2015, 92, 161-169. [CrossRef]

(C) 2016 by the authors; licensee MDPI, Basel, Switzerland. This article is an open access article distributed under the terms and conditions of the Creative Commons Attribution (CC-BY) license (http://creativecommons.org/licenses/by/4.0/). 